Fecha de entrega: 28 de noviembre de 2008

Fecha de aprobación: 6 de abril de 2009

\title{
LA TAREA DE RECONOCER EL MULTICULTURALISMO COLOMBIANO ${ }^{1}$
}

\section{THE TASK OF RECOGNISING THE COLOMBIAN MULTICULTURALISM}

\author{
Edgar Antonio López ${ }^{2}$
}

\section{Resumen}

Desde que la Constitución de 1991 estableció que Colombia es un país multi-étnico y pluri-cultural se constata un creciente interés en algunos sectores académicos y políticos por la cuestión del multiculturalismo. Esta investigación describe la historia del desconocimiento de la pluralidad cultural en Colombia y examina la tensión actual vivida por el Estado colombiano, que en su tarea de procurar la libertad y la igualdad de los ciudadanos debe buscar a la vez el reconocimiento de los derechos colectivos. La experiencia colombiana evidencia los límites de la legislación liberal, basada tradicionalmente en los derechos individuales y sirve como espacio para contextualizar la discusión que en torno al papel del Estado ante los derechos colectivos han desarrollado recientemente los filósofos morales partidarios del comunitarismo y aquellos partidarios del universalismo de los derechos individuales.

\section{Palabras clave}

Pluralidad, cultura, Colombia, ley, indígena, participación, reconocimiento, Constitución.

\begin{abstract}
Since the Constitution of 1991 established that Colombia is a multiethnical and pluricultural country, there is a growing interest about the multiculturalist issue among academic and political sectors. These investigations describe the history of the ignorance about the
\end{abstract}

1 Este artículo presenta parte de los resultados de la investigación: "Calidad de vida y dignidad humana en el debate bioético ante la libertad cultural”, desarrollada por la Facultad de Teología y el Instituto de Bioética de la Pontificia Universidad Javeriana.

2 Facultad de Teología. Pontificia Universidad Javeriana. 
cultures of Colombia and examines today's tension lived by the colombian State, which, in his task of fighting for the liberty and equality of the citizens, it has to recognise also the colective rights. The colombian experience shows the limits of the liberal legislation based traditionallly on individual rights and gives us a context for the discussion about the role of the State in the issue of the colective rights. The moral philosophers that support comunitarism and the ones that support the universality of the human rights have recently focussed on this issue.

\section{Key words}

Plurality, culture, Colombia, law, native, participation, recognition, Constitution.

\section{Historia del desconocimiento de la pluralidad cultural en Colombia}

\begin{abstract}
A lo largo de la compleja historia de Colombia, los procesos culturales han devenido una admirable diversidad, diversidad que aumentó súbitamente con la invasión ibérica a tierras americanas en los últimos años del siglo XVI y con los procesos de esclavismo, cristianización y castellanización que se desarrollaron a partir de la ola migratoria iniciada en Colombia hacia el año 1500 . Estos procesos constituyen una dinámica de intercambio cultural que, pese a su sentido inhumano y asimétrico, terminó por contribuir al enriquecimiento de la sociedad a través de la incorporación de elementos europeos y africanos a la amalgama de los ya existentes en el territorio colombiano.
\end{abstract}

En los años siguientes a los desembarcos de 1500 se calcula que en Colombia han desaparecido aproximadamente 70 lenguas autóctonas $^{3}$, dato que evidencia la aniqui-

3 "Según estudios realizados por el Centro Colombiano de Estudios de Lenguas Aborígenes (CECELA), de la Universidad de los Andes, en el siglo XX las lenguas indígenas que han desaparecido son: el Kankuamo, de la familia Chibcha, de la Sierra Nevada de Santa Marta. Opón-carare y Pijao de la familia Caribe, del Valle del río Magdalena, y Resigaro ladora empresa de imposición de códigos lingüísticos y culturales occidentales. A pesar de ella, hoy Colombia cuenta con catorce familias lingüísticas vivientes, a saber: Arawac, Caribe, Chibcha, Guahibo, Tucano oriental, Tucano occidental, Witoto, Chocó, Saliva-Piaora, Macú-Pinave, Barbacoa, Quechua, Tupiguaraní y Bora. Las lenguas así agrupadas suman más de treinta, pero también existen otras lenguas independientes -y muy importantes- como el Andoque, el Cofán, el Guambiano, el Kamsá, el Páez, el Yagua y el Ticuna ${ }^{4}$.

Las empresas de la conquista americana se desarrollaron en nombre de la Corona española pero con fondos provenientes de

de la familia Arahuaca, en la Amazonía”. www. etniasdecolombia.org/periodico.

4 Estas lenguas se agrupan de la siguiente manera: Arawac (Wayuu, Curripaco, Achagua, Piapoco, Tariano, Cabiyarí y Yucuba); Caribe (Yuco y Carijona); Chibcha (Uwa, Wiwa, Arhuaco y Cogui); Guahibo (Cuiba, Hitnu y Sikuani, Tucano Oriental (Macuna, Tanimuca, Yurutí, Cubeo y Desano; Tucano Occidental como el Siona y Koreguaje; Witoto como el Ocaina; Choco (Embera y Wounana); Saliva-Piaroa; Macú- Pinave (Nukak), y Barbacoa (Awa); Quechua (Inga) y Tupi-Guarani (Cocama); Bora (Miraña); y algunos pertenecientes a familias independientes como el Andoque, Cofán, Guambiano, Kamsá, Páez, Yagua y Ticuna. www.etniasdecolombia.org/periodico. 
la empresa privada, por lo que los encomenderos recibieron en contraprestación no sólo tierras, sino indígenas como retribución por los servicios prestados. Ante los abusos de los que fueron objeto las comunidades indígenas, la Corona desarrolló una política indigenista expresada en leyes de protección, que no obstante, "fueron un monumento a la ineficacia” (Colmenares, 1989, p. 119), como lo muestra el rápido descenso demográfico de la población indígena a causa del exterminio y la sobrehumana explotación.

Las comunidades afro-descendientes constituyen otro importante grupo que enriquece el acervo cultural colombiano y que, al lado de las comunidades indígenas, ha sido objeto de discriminación durante siglos. "Aun cuando la mayoría de la población colombiana se define como mestiza, Colombia es el tercer país de las Américas con el mayor número de descendientes de africanos" (Helg, 2004, p. 23). Esta riqueza cultural se explica por la aberrante importación de habitantes del África Occidental y Central para satisfacer la demanda de las minas, haciendas, conventos y otras instituciones que en el territorio colombiano fueron reemplazando progresivamente la explotación de la diezmada población indígena por la de esclavos negros.

La importación de personas de piel negra constituyó una empresa muy lucrativa que se expandió a partir del principio de proporcionalidad uno a tres, según el cual el trabajo de un negro superaba por factor de tres al de un solo indio, "principio que rápidamente se convirtió en la opinión común, creó la convicción en los funcionarios y colonos, especialmente en el siglo XVIII, de que la trata e introducción masiva de negros era la panacea para la economía del virreinato" (Palacios, 1989, p. 154).

Este principio, no obstante, escondía un importante elemento de diferenciación, pues las sociedades africanas, de las que eran arranca- dos quienes se iban a convertir en esclavos, se caracterizaban por una mayor sofisticación de las técnicas de trabajo con respecto a las indígenas. Paradójicamente este grado de desarrollo de las comunidades negras constituyó una razón de mayor sufrimiento para sus miembros.

Debe notarse, sin embargo, que desde la época de la colonia y hasta ahora, el trato hacia la población indígena no ha sido el mismo que el recibido por los afrodescendientes. En la colonia se entendía que se trataba de dos clases diferentes de seres: "los indígenas eran una especie de 'regalo de la Naturaleza' que no implicaba erogación alguna; los esclavos negros suponían una inversión y, obviamente, requerían cierta atención y cuidados mínimos para lograr un mayor beneficio" (Palacios, 1989 , p. 165). Esto explica bien la contradictoria tradición colonial del solícito cuidado hacia los esclavos por parte de sus amos, que no podían descuidar la inversión hecha.

La discriminación social hacia las personas que pertenecen a las comunidades indígenas $\mathrm{y}$ afro-descendientes constituye una característica que recorre la historia de Colombia:

Desde los principios de la Colonia, el blanco ha sido igualado a la cultura occidental, el catolicismo, el matrimonio legal y las profesiones no manuales. $\mathrm{Al}$ indio se le ha igualado a lo salvaje, la superstición, la propiedad comunal y la tierra. Por su parte, el negro ha sido el bárbaro, la brujería, lo sensual y lo sexual. El concubinato, y el trabajo manual. Entre las tres puntas de la pirámide, se encuentra una multitud de mezclas raciales consideradas siempre inferiores al blanco pero superiores al negro y al indio "puros" (Helg, 2004, p. 24). 
Sumada a estas discriminaciones, la discriminación de las mujeres, constituye uno de los obstáculos más grandes para la equidad política, social y económica. Las diferencias sociales basadas en diferencias étnicas y culturales vienen del ordenamiento social colonial "impuesto violentamente sobre sociedades de suyo complejas, queriendo despojarlas de sus propios criterios de estima y de privilegio social. La dualidad étnica y cultural aparece entonces como el trasfondo decisivo de las diferenciaciones sociales" (Colmenares, 1989, p. 143). Esta dualidad, que deviene discriminación, se traduce actualmente en una presión, muchas veces acompañada de violencia brutal, sobre las nuevas generaciones de indígenas y de afrocolombianos para que abandonen sus costumbres, su lengua y -sobre todo- su territorio.

La Constitución de Cúcuta de 1821 garantizaba la libertad, la seguridad, la propiedad y la igualdad de los ciudadanos de la Gran Colombia, "pero no mencionaba la raza y el género ni trataba de manera explícita a los indígenas y a los esclavos, cuya condición fue el objeto de una legislación separada" (Helg, 2004, p. 27). Sin embargo, tal legislación no favoreció los intereses colectivos de estos grupos culturales, pues mientras la Ley del 11 de octubre de 1821 abolió tanto el tributo como el servicio personal y concedió algunos derechos a los indígenas, preparó también la liquidación de sus resguardos al establecer que estos debían ser divididos entre las familias bajo la forma de propiedad privada con la expectativa de superar así su condición de miseria. "El resguardo, como institución colonial, fue percibido como un rezago de ese pasado ignominioso y como una muralla que impedía la expansión de la "Civilización"” (Pineda, 2002, p. 12). De la lucha contra él se beneficiaron muchos hacendados y municipios que se apropiaron legalmente de los territorios indígenas. Por su parte, la Ley del 21 de julio de 1821 declaró la libertad de nacimiento para los hijos de las esclavas, pero estableció la obligación de trabajar hasta los 18 años para los amos de sus madres como retribución de la educación, el abrigo y la alimentación recibidos (Helg, 2004, p. 28).

La Constitución de 1886 quiso afianzar la unidad nacional y suprimir las guerras civiles, propósito que no se alcanzó durante los ciento cinco años de su vigencia ni ha sido alcanzado hasta ahora. No se ocupó de los intereses de las comunidades étnicas autóctonas ni afrodescendientes, pues su énfasis en la reconstrucción de la nación hizo de la unidad nacional un prurito que habría de conseguirse a pesar de y en contra de la diversidad existente. Así lo comenta el Senador Carlos Gaviria Díaz en el prólogo del libro La jurisdicción especial indígena, de Esther Sánchez e Isabel Jaramillo (2001):

El propósito del Constituyente de 1886 de "reconstruir" a Colombia como un Estado unitario, no estaba circunscrito al ámbito de la competencia política, desvertebrada en el rígido federalismo de la Constitución de Rionegro. Se trataba de crear, por la fuerza del mandato soberano, una comunidad homogénea no sólo por el sometimiento a una sola instancia legislativa, sino por la aspiración común a un mismo destino.

A la Constitución de 1886, llamada la Constitución de la Regeneración Conservadora, se puede aplicar entonces lo que Gabriel Melo comenta de las primeras constituciones colombianas (1986), que "no se escribieron pensando en nuestra gente... sus autores se encerraron a discutir doctamente, sobre temas que nada tenían que ver con lo que estaba sucediendo fuera del recinto en donde disertaban". 
La Ley 89 de 1890 dividió a los indígenas en: aquellos ya establecidos en resguardos y comunidades, reducidos así a la vida civilizada, y los todavía salvajes, "cuya reducción y evangelización eran pagadas por el Estado pero encargada a misiones católicas" (2004, 30). Las comunidades indígenas semi-civilizadas podían conservar sus instituciones tradicionales pero no podían hacer transacciones de sus tierras sin la tutela del Estado. A la sombra del espíritu de la Constitución de 1886 esta ley mantuvo una percepción negativa de los indígenas y reivindicó hacia ellos el modelo colonial, razón por la cual "quedaron al margen de la 'legislación general' de la República, bajo la tutela de las misiones católicas, y fueron considerados como 'menores de edad' en lo que atañe al régimen civil y penal de la Nación" (Pineda, 2002, p. 12). La tutela de estas comunidades encomendada a la iglesia católica refleja bien el desconocimiento de los indígenas como autónomos sujetos de derechos y el espíritu de unificación cultural alrededor del cristianismo católico, propio de la regeneración conservadora.

La política de eliminación de los resguardos, iniciada en 1890, se prolongó en la Ley 5 de 1905 y luego en la Ley 104 de 1919, los despojos continuaron hasta en las más progresistas administraciones presidenciales, pues "desde el Estado se fomentó una política de negación de las culturas y de las sociedades indígenas, en cuanto que se percibía... a los indios y a los negros como estigmas de inferioridad racial" (Pineda, 2002, p. 13). Sin embargo, la Ley 89 había sentado un importante precedente para los pueblos indígenas "en cuanto definía su existencia si se demostraba su convivencia en comunidad" (Pineda, 2002, p. 13). Este aspecto sirvió luego para defender los derechos comunitarios de los pueblos indígenas y posibilitó los logros obtenidos en la Constitución de 1991.
Durante casi todo el siglo XIX y parte del siglo XX, la sociedad colombiana, liberada ya de la hegemonía española, hizo suya la tarea de construir una identidad nacional, pero en el proceso los indígenas, los negros y las mujeres no tuvieron mayor participación. El esfuerzo criollo por crear una identidad nacional en Colombia a partir de la cultura dominante conoció importantes manifestaciones culturales contrarias, como lo expone María Cristina Rojas en un artículo sobre la formación de la identidad nacional en Colombia durante el siglo XIX, publicado en el año de 1997.

La obra del poeta negro Candelario Obeso contiene importantes denuncias a la manipulación de la que fueron objeto las negritudes durante las guerras civiles del siglo XIX:

Ricen que hay guerra con los cachacos, y a mí me chocan los Zambapalo... Cuando los goros si fui sordao pocque efendía mi humilde rancho... $\mathrm{Si}$ acguno quiere trepacse en arto, buque ejcalera por otro lao... Ya pasó er tiempo re loj eclavos: somo hoy tan libre como lo branco... ¿Quieren la guerra con los cachacos? Yo no me muevo re aquí e mi rancho (Rojas, 1997, p. 55).

La obra de Soledad Acosta de Samper encarna también la resistencia de las mujeres del siglo XIX al proyecto criollo, de cariz masculino, como único camino reconocido para alcanzar la construcción de la identidad nacional. En la novela Un chistoso de Aldea, Soledad muestra la ambivalencia que tuvo para las mujeres la lucha por la independencia, pues significó una lucha contra la opresión española, pero continuaron bajo la opresión masculina. "Acusado de anti-patriota por defender a una mujer española, Justo se defiende diciendo que aunque patriota no 
puede resistir el mal comportamiento contra la mujer" (Rojas, 1997, p. 56).

La discriminación hacia comunidades negras e indígenas a lo largo de la historia llevó a importantes movimientos de reivindicación que van desde los primeros combates de resistencia indígena contra las huestes españolas en el siglo XVI y la fundación de los primeros palenques por parte de los esclavos fugitivos, pasando por la conformación de grupos guerrilleros indígenas como el Quintín Lame, hasta las luchas de los movimientos indígenas que desde 1970 "tomaron como meta la recuperación de la tierra, la lengua y la cultura" (Pineda, 2002, p. 13).

Sin embargo, los grupos afrodescendientes no contaron con los vínculos y tradiciones que permitieron al movimiento indígena resistir de manera continua la discriminación. Acaso por haber sufrido un desarraigo que como ha ocurrido con la población desplazada hoy por la guerra, los arrancó de su tierra y desmembró sus comunidades. Sólo hacia 1980 las movilizaciones de las negritudes se hicieron visibles para la sociedad colombiana, que entonces cobró conciencia de la importancia cultural de estos grupos.

\section{Necesidad del reconocimiento de la pluralidad cultural en Colombia}

El proyecto de forjar una nación está íntimamente relacionado con el de forjar una identidad, pues el ejercicio de reconocerse miembro de una comunidad política es posible gracias al de distinguirse de los miembros de otras comunidades y de otros proyectos ${ }^{5}$.

5 A esto se refiere el concepto de nación como comunidad política imaginada, de Benedict Anderson: "'Imaginada' porque a pesar de que no todos los miembros se conocen, en la mente de cada uno existe la sensación de que participan de algo común. Es una 'comunidad' porque, a pesar de las desigualdades, la nación
Sin embargo, la historia colombiana evidencia enormes vacíos de reconocimiento cultural en el papel que jugaron las mujeres, los negros y los indígenas en el proceso de construcción de la identidad. "Al tomar en consideración la construcción de identidades se puede entender el porqué los criollos americanos más que imaginar una comunidad fraternal... imaginaron una comunidad excluyente cuyo resultado fue una nación altamente fragmentada" .

La historia colombiana, atravesada por el desconocimiento de los derechos y las necesidades de las minorías étnicas y culturales, y el convulsionado escenario político en que la pluralidad cultural ha sido recientemente admitida y valorada, muestran el carácter necesario que dicho reconocimiento comporta para una sociedad fragmentada que busca su identidad como proyecto en permanente construcción.

El filósofo comunitarista Charles Taylor (2001, p. 43) señala que el reconocimiento por parte de otros juega un importante papel en la forja de la propia identidad si ésta se entiende como "la interpretación que hace una persona de quién es y de sus características definitorias fundamentales como ser humano"; "consideramos lo que entendemos por identidad: es quiénes somos, 'de dónde venimos" (Taylor, 2001, p. 54) y a la vez como el ideal de la autenticidad (véase: Taylor, 2001, 47); En este sentido Taylor (2001, p. 50) dice suscribir la concepción de Lionel Trilling expuesta en Sincerity and authenticity. "Hay un cierto modo de ser humano que es mi modo. He sido llamado a vivir mi vida de esta manera, y no para imitar la vida de

siempre se concibe como una fraternidad horizontal" (Rojas, 1997, p. 49).

6 María Cristina Rojas critica a Anderson por no dar un lugar central a la noción de identidad, base de la concepción de nación (Rojas, 1997, p. 50). 
ningún otro". Por esta razón, resulta tan perjudicial la ausencia de reconocimiento como el reconocimiento limitante o degradante, del que han sido objeto en la historia colombiana los negros, los indígenas, las mujeres y todos los grupos pertenecientes a minorías marginadas culturalmente. En general éste es el sino propio de todos los pueblos colonizados: "El reconocimiento igualitario no sólo es el modo pertinente a una sociedad democráticamente sana. Su rechazo puede causar daños a aquellos a quienes se les niega... No dar este reconocimiento puede constituir una forma de opresión" (Taylor, 2001, pp. 58-59).

En la dinámica de la autenticidad las relaciones resultan fundamentales para el auto-descubrimiento y la autoafirmación, mientras que "la proyección sobre el otro de una imagen inferior o humillante puede en realidad deformar y oprimir hasta el grado en que esa imagen sea internalizada" (Taylor, 2001, p. 58). El proceso histórico de forjar una identidad nacional con base en un modelo europeo y masculino de cultura durante siglos imprimió en las poblaciones femeninas, negras e indígenas una imagen de inferioridad y sólo podía dar como resultado una sociedad fragmentada. "Una mirada a la historia de Colombia, a mediados del siglo XIX, nos permite concluir que inventamos una nación fragmentada más que unificada" (Rojas, 1997, p. 56).

La modernidad que removió las bases de las sociedades jerárquicas tradicionales y desplazó la ideología del honor que hacía ver bien las diferencias sociales, abrió paso al sentido igualitarista de los derechos universales, pero sólo fue parcialmente aceptada por la sociedad colombiana, que hizo suyos los procesos de modernización sin renunciar a su inveterada manera excluyente de organizarse en lo político (véase: Jaramillo, 1998, pp. 27-57). Por esta razón el proceso de constitución de la identidad nacional en Colombia obedece a un proceso de "inclusión abstracta y exclusión concreta" (Rojas, 1997, p. 50), como bien señala Jesús Martín.

No obstante, la preocupación por la identidad individual y el reconocimiento colectivo de la que ésta depende es un rasgo característico de las sociedades que se dejan permear por el proyecto moderno de la igualdad en dignidad que comparte todo ser humano. La concepción del sí mismo más allá de la escala social jerárquica, como fidelidad con la propia originalidad, fue atribuida por Herder, no sólo a las personas sino también a los pueblos que buscan ser fieles a su cultura y la transmiten a otros. La fidelidad con la propia manera de ser es un empeño que evidencia la estrecha relación existente entre identidad y reconocimiento, rasgo esencial de la vida humana.

Deseo valerme del término lenguaje en su sentido más flexible, que no sólo abarca las palabras que pronunciamos sino también otros modos de expresión con los cuales no definimos [...] Este rasgo decisivo de la vida humana es su carácter fundamentalmente dialógico. Nos transformamos en agentes humanos plenos, capaces de comprendernos a nosotros mismos y por tanto de definir nuestra identidad por medio de nuestra adquisición de enriquecedores lenguajes humanos para expresarnos... Pero aprendemos estos modos de expresión mediante nuestro intercambio con los demás... La génesis de la mente humana no es, en este sentido, monológica (no es algo que cada quien logra por sí mismo), sino dialógica (Taylor, 2001, pp. 52-53).

La propia identidad se define en la búsqueda de la autenticidad, pero siempre la realización propia está referida a los otros en forma dialógica; dirá Taylor (2001, p. 55) “mi propia 
identidad depende, en forma crucial, de mis relaciones dialógicas con los demás". No obstante, y es una paradoja, la constitución de la identidad colombiana luego de la independencia política de España se inspiró en la recién inaugurada visión moderna de la humanidad como comunidad universal y resultó a la vez marcadamente excluyente:

El proyecto de creación de una civilización mestiza, gobernada bajo el principio de la fraternidad, no significó, sin embargo, la proclamada inclusión de todas las razas, clases y sexos... Sólo la identidad criolla sirvió como modelo a la cual tendrían que acomodarse los demás grupos so pena de quedar excluidos del proyecto nacional (Rojas, 1997, p. 51).

Según Taylor, con la modernidad, al lado de la visión política de igualación a partir del reconocimiento de una dignidad universal, se tiene también el desarrollo del concepto de identidad, del que surge la política de la diferencia. En este sentido, los comunitaristas enfatizan la necesidad de atender a la vez a la igualdad y a la diferencia para que la condición de ser distinto no sea asimilada por una identidad mayoritaria en contra de la autenticidad, como ocurrió en Colombia con el proyecto criollo de identidad nacional. Es así como el comunitarismo da prioridad a la identidad diferenciada sobre la identidad compartida:

Con la política de la dignidad igualitaria lo que se establece pretende ser universalmente lo mismo, una "canasta" idéntica de derechos e inmunidades; con la política de la diferencia, lo que pedimos que sea reconocido es la identidad única de este individuo o de este grupo, el hecho de que es distinto de todos los demás (Taylor, 2001, p. 61).

El caso colombiano muestra que no es fácil lograr la compatibilidad de ambas visiones políticas y que el reconocimiento de la diferencia es condición para aceptar la dignidad universal.
La política de la diferencia está llena de denuncias de discriminación y de rechazos a la ciudadanía de segunda clase, lo que otorga al principio de la igualdad universal un punto de enclave en la política de la dignidad. Pero una vez dentro, por decirlo así, resulta muy difícil incorporar sus demandas a esa política; pues exige que demos reconocimiento y status a algo que no es universalmente compartido [...] Estos dos modos de política que comparten el con- cepto básico de igualdad de respeto entran en conflicto (Taylor, 2001, pp. 61, 67).

La condición de colombiano fue asimilada históricamente con la condición de criollo, que se consideraba entonces portadora de una dignidad superior a la de los negros y a la de los indígenas, por lo que estos deberían perder su especificidad cultural para insertarse en el espíritu universal de la humanidad.

En contraste con esto afirma Taylor (2001, p. 62): "La demanda universal impele a un reconocimiento de la especificidad. La política de la diferencia brota orgánicamente de la política de la dignidad universal”. Lo que está universalmente presente-la identidad-debe ser reconocido a través del reconocimiento de lo peculiar de cada identidad y esto fue lo que no se hizo en el proceso de forja de la identidad nacional en Colombia. El proyecto republicano de nación que siguió a la independencia no rompió la dinámica de 
vasallaje y de desconocimiento al que habían sido históricamente sometidas las mayorías femeninas, indígenas y negras. Los criollos optaron por la defensa de la civilización europea como camino seguro para construir la nación y la identidad nacional.

La civilización mestiza fue concebida como un proceso de blanqueamiento en el cual no quedaran vestigios de las razas indígena y negra... La tarea de construir una nación civilizada tampoco requería la presencia política de las mujeres. El mejoramiento de su condición dependería de la suerte de los hombres y de su concurso en el ámbito privado del hogar (Rojas, 1997, p. 51).

La paradójica exclusión y destrucción cultural de las que fueron objeto quienes estaban llamados a la inclusión universal en nombre de la igualdad muestra la incompleta aceptación del proyecto moderno por parte de la clase criolla dominante. Mientras la política del universalismo reconoce la igualdad en dignidad de todo ciudadano y niega la discriminación entre diferentes estratos jerárquicos de ciudadanía, en el caso colombiano no sólo se transgredió el principio de no discriminación, sino se condenó a los discriminados a un total desconocimiento cultural por parte de los otros y -lo que es más grave- por parte de ellos mismos.

El caso colombiano de igualación cultural a que respondió el proyecto de nación introdujo otro problema, pues la igualación no sólo afectó los derechos civiles y políticos sino se extendió a la esfera económica. "Las personas a quienes la pobreza ha impedido sistemáticamente aprovechar de lleno sus derechos de ciudadanía han sido relegadas, según esta opinión, a la categoría de segunda clase" (Taylor, 2001, p. 60). En este sentido conviene señalar que una sociedad fragmentada como la co- lombiana debe demandar del Estado no sólo la protección de las costumbres, las creencias y la lengua de las comunidades marginadas culturalmente, sino la implementación de políticas públicas parcializadas que permitan disminuir el desequilibrio introducido históricamente. A propósito de esto, Taylor ve un paralelismo entre la parcialidad introducida al implementar políticas redistributivas, como respuesta a la preocupación por la permanencia de algunas personas en la segunda clase de ciudadanía por razones económicas, y la necesidad de favorecer a algunos grupos mediante un trato diferenciado para evitar la discriminación. Taylor ve tal paralelismo en el pensamiento de Will Kymlicka, quien:

[...] trata de defender cierto tipo de política de la diferencia [...] pero desde una base que se encuentra firmemente ubicada dentro de la teoría de la neutralidad liberal [...] En ciertas circunstancias, para las poblaciones en desventaja, la integridad de la cultura puede requerir que les asignemos mayores recursos o derechos que a los demás. El argumento es perfectamente paralelo al que se ha establecido en relación con las desigualdades económicas (2001, p. 64).

De esta forma los comunitaristas advierten bien la conexión que media entre la discriminación política por razones culturales y la discriminación económica que algunas veces preocupa al liberalismo. John Rawls, epígono del liberalismo de los derechos individuales, condiciona el ideal de una sociedad justa a los principios de la libertad y de la diferencia:

1. Toda persona tiene igual derecho a un régimen plenamente suficiente de libertades básicas iguales, que sea 
compatible con un régimen similar de libertades para todos. 2. Las desigualdades sociales y económicas deben satisfacer dos condiciones: primero, deben estar ligadas a empleos y funciones abiertas a todos bajo condiciones de igualdad de oportunidades; y segundo, deben beneficiar a los miembros menos favorecidos de la sociedad (Rawls, 1997, p. 27).

La preocupación comunitarista, en cambio, se enfoca sobre la última parte del segundo principio, que propende por la protección de los menos favorecidos.

No es fácil armonizar el universalismo que previene contra la discriminación y el comunitarismo que busca un trato diferenciado, de ahí las críticas mutuas entre estas dos maneras de interpretar los derechos. A la política de la diferencia se le critica porque "viola el principio de la no discriminación" (Taylor, 2001, p. 67) y a la política de la dignidad universal porque "niega la identidad cuando constriñe a las personas para introducirlas en un molde homogéneo que no les pertenece de suyo" (Taylor, 2001, p. 67). Los comunitaristas buscan corregir la ceguera de la política de la dignidad universal, que "luchaba por unas formas de no discriminación que eran enteramente ciegas a los modos en que difieren los ciudadanos" (Taylor, 2001, p. 62). En la política de la diferencia se redefine la no discriminación, exigiendo que se haga de las distinciones "la base del tratamiento diferencial” (Taylor, 2001, p. 62).

Aunque medidas que favorecen algunos miembros de grupos marginados en el acceso a la educación o al empleo puedan ser vistas como injustas desde una perspectiva igualitaria, en realidad la política de la diferencia no niega la política universal de la dignidad, y parece ser el camino por el que se ha de concretar el reconocimiento de la pluralidad cultural en Colombia.

\section{La participación en el proceso de reconocimiento de la pluralidad cultural}

La imposición de algunas formas culturales sobre otras se evidencia en las distintas formas de colonialismo que siempre cuentan con un arma muy poderosa en la inoculación de una auto-imagen inferior en los colonizados y pervive en la discriminación occidental hacia quienes proceden de otras culturas. Taylor suscribe la tesis de Frantz Fanon: "Los grupos dominantes tienden a afirmar su hegemonía inculcando una imagen de inferioridad a los subyugados" (Taylor, 2001 p. 97). He ahí la importancia de las políticas de educación multicultural: "Así como todos deben tener derechos civiles iguales e igual derecho al voto, cualesquiera que sean su raza y su cultura, así también todos deben disfrutar de la suposición de que su cultura tradicional tiene un valor" (Taylor, 2001, p. 100).

La permanencia de estas relaciones de dominación cultural justifica una profunda reflexión orientada a reivindicar la supervivencia cultural de grupos en desventaja y el necesario reconocimiento por parte de todos del valor de las diferencias culturales.

La premisa fundamental de estas demandas es que el reconocimiento forja identidad... [y] En calidad de hipótesis la afirmación es que todas las culturas que han animado a sociedades enteras durante algún periodo considerable tienen algo importante que decir a todos los seres humanos (Taylor, 2001, pp. 97-98). 
Es razonable suponer que las culturas que han aportado un horizonte de significado para gran cantidad de seres humanos, de diversos caracteres y temperamentos, durante un largo periodo -en otras palabras, que han articulado su sentido del bien, de lo sagrado, de lo admirable- casi ciertamente deben tener algo que merece nuestra admiración y nuestro respeto (Taylor, 2001, p. 100).

Esto implica ir más allá del mero conocimiento de las diversas formas culturales y alcanzar el campo jurídico.

Desde una perspectiva multicultural la infravaloración de cualquier grupo humano aparece no sólo como equivocada fácticamente por no reconocer la diversidad, sino como moralmente incorrecta por rechazar el principio fundamental que reconoce el mismo potencial común a todos los seres humanos. El sentido moderno de la dignidad humana como capacidad para dirigir la propia vida en forma autónoma ha sido en Colombia sistemáticamente negado tanto a las mujeres como a las comunidades afrodescendientes e indígenas. Esta dignidad universal se ubica en el mismo nivel del potencial de moldear y definir la propia identidad, "como individuos y como cultura” (Taylor, 2001, p. 65).

Los grupos marginados deben participar en la forja de la identidad nacional para que ésta responda a los parámetros modernos, pero debe tenerse muy presente que las críticas más radicales hechas desde la política de la diferencia al liberalismo de la dignidad igualitaria coinciden al señalar que los liberalismos no son sino reflejo de algunas culturas particulares. Para Taylor (2001, p. 67), la ceguera de la dignidad igualitaria es reflejo de una cultura hegemónica y evidencia que "la sociedad supuestamente justa y ciega a las diferencias no sólo es inhumana (en la medida en que suprime las identidades) sino también, en una forma sutil e inconsciente, resulta sumamente discriminatoria". Sin embargo, lo más preocupante para él es que el liberalismo no sea más que "un particularismo que se disfraza de universalidad" (Taylor, 2001, p. 68). Esta crítica parece válida y oportuna en lo que se refiere a la forma androcéntrica y eurocéntrica propia del proyecto excluyente de forjar identidad nacional a partir del discurso de la dignidad universal.

No se debe desconocer la estima de la que se es objeto por parte de los demás si se trata de alcanzar "un sistema caracterizado por la igualdad, la reciprocidad y la unidad de propósito" (Taylor, 2001, p. 67) en que todos los ciudadanos sean honrados por igual. En este sentido Rousseau había propuesto ya el Estado del contrato social, en que "el pueblo debe ser, a la vez, soberano y súbdito" (Taylor, 2001, p. 77), para lo cual la libertad, la indiferenciación de papeles de los ciudadanos y el sólido propósito común deben ser inseparables. Sin embargo, con esto deja a cada quien en dependencia con respecto a la voluntad general -como medida para prevenir dependencias bilaterales- y no debe olvidarse que "ésta ha sido la fórmula para las formas más terribles de tiranía homogeneizante" (Taylor, 2001, p. 77).

Si bien Hegel y Rousseau aciertan al afirmar que "la lucha por el reconocimiento sólo puede encontrar una solución satisfactoria, y ésta consiste en el régimen del reconocimiento recíproco entre iguales" (Taylor, 2001, p. 76), tal régimen debe ser ampliado para que en él se pueda reconocer la diferencia. Esto falló en el caso colombiano en el que el reconocimiento sólo se dio entre las clases culturalmente dominantes y para los otros hubo desconocimiento y discriminación. Desde la óptica liberal los derechos individuales siempre deben ocupar el primer lugar, pues "una teoría de los derechos correctamente entendida no es, de ninguna manera, ciega frente a las diferencias culturales" (Haber- 
mas, 1999, p. 194) y en ella las provisiones no discriminatorias deben tener precedencia sobre las metas colectivas, pero el reconocimiento de las diferencias culturales y la corrección de las discriminaciones sociales y económicas que se derivan de la marginación cultural deben ser condiciones para que el proyecto liberal se concrete en Colombia.

Universalistas como John Rawls y Jürgen Habermas proponen que el trato recíproco e igualitario, por ser procesal, guarda independencia con respecto a los fines sustantivos de la vida, pero comunitaristas como Taylor y Walzer muestran que eso sólo se puede lograr si se reconocen las diferencias culturales y no se colige de ellas la discriminación social, política y económica. La neutralidad de la sociedad y del Estado ante las concepciones de vida buena históricamente desconocidas y políticamente marginadas debe ser entonces reconsiderada para que la meta universal del liberalismo pueda ser alcanzada sin pasar por encima de las metas colectivas de las minorías, pues "una sociedad liberal se distingue como tal por el modo en que trata a las minorías" (Taylor, 2001, p. 88), en este sentido los principios de la teoría de la justicia deberían proponerse en orden inverso, comenzando por el favorecimiento de lo más vulnerable.

Para Taylor una sociedad puede perseguir con ahínco ciertas metas colectivas sin dejar por ello de ser liberal, ya que en la diversidad debe respetar las divergencias de aquellos que no comparten sus metas comunes dejando a salvo los derechos fundamentales. "Hay que distinguir las libertades fundamentales, las que nunca deben ser infringidas [...] de los privilegios y las inmunidades que a pesar de su importancia se pueden revocar o restringir por razones de política pública" (Taylor, 2001, p. 89).

Para superar un liberalismo "culpable de las acusaciones que le dirigen los partidarios de la política de la diferencia” (Taylor, 2001, p.
97), existen otros modelos de sociedad liberal que no aplican de manera uniforme las reglas derivadas de los derechos y no desconocen la importancia de las metas colectivas. Estas formas de liberalismo alternativo, preconizadas por Taylor y a las cuales podría aproximarse cada vez más la organización política de la sociedad colombiana, distinguen entre los derechos fundamentales inalienables y otros que pueden concretarse de diversas maneras.

Estas modalidades del liberalismo están dispuestas a sopesar la importancia de ciertas formas de trato uniforme contra la importancia de la supervivencia cultural, y optan a veces a favor de esta última... No constituyen modelos procesales de liberalismo, pero se fundamentan en buena medida en los juicios acerca de lo que es una vida buena (Taylor, 2001, p. 91).

La versión rígida del liberalismo que le apuesta a la neutralidad puede todavía ser defendida pretendiendo que encarna el ideal de "un terreno neutral en que podrían unirse y coexistir personas de todas las culturas" (Taylor, 2001, p. 92), pero esto sería desconocer importantes visiones culturales como las indígenas, en que "no puede hablarse siquiera de separar la política y la religión en la forma como hemos llegado a esperar que acontezca en la sociedad liberal de Occidente" (Taylor, 2001, p. 92).

Para Taylor el liberalismo tradicional no puede reunir a todas las culturas en cuanto no es sino la expresión política de una cultura occidental incompatible con otras. "Además, como bien lo saben muchos musulmanes, el liberalismo occidental no es tanto una expresión de la visión secular posreligiosa que se popularizó entre los intelectuales liberales, cuanto un retoño más orgánico del 
cristianismo" (Taylor, 2001, p. 92). No cabe entonces atribuir al liberalismo la neutralidad cultural con la que de ordinario se le asocia, pues se trata de un credo combatiente (Taylor, 2001, p. 93).

Ante las críticas comunitaristas el Estado democrático de derecho se resquebraja porque está cimentado sobre la base de los derechos individuales. Por esta razón pensadores como Taylor y Walzer cuestionan la comprensión moderna de la libertad, de cuño individualista y proponen una segunda versión del liberalismo que incluya el respeto a formas de vida y a concepciones del mundo amenazadas por ser propias de los grupos en desventaja.

La propuesta de Taylor consiste en pasar de un liberalismo ciego a la diferencia a un liberalismo que parta de la diferencia, pero a ella se oponen pensadores universalistas de la talla de Habermas, para quien una teoría de los derechos, formulada en términos individualistas, responde a las luchas colectivas por la identidad sin que sea necesario pensar otro tipo de liberalismo.

En el punto decisivo Taylor se mantiene ambiguo. Distingue dos versiones del Estado democrático de derecho que denomina liberalismo 1 y liberalismo 2. Esta denominación sugiere que la segunda versión favorecida por él tan sólo corrige una comprensión inadecuada de los principios liberales. Si se mira más de cerca, la versión de Taylor ataca, empero estos principios en sí mismos (Habermas, 1999, p. 191).

Habermas reconoce la insuficiencia -señalada por algunos comunitaristas- que tiene la distribución de los bienes colectivos para garantizar el reconocimiento de las identidades colectivas y la igualdad de derechos de las particulares formas de vida. También propone que desde esta perspectiva la equidad depende de la identidad cultural, pero advierte que antes de poner a la par las condiciones de vida de los menos aventajados con los demás sectores de la sociedad se debe asegurar las identidades colectivas de todos los grupos que conforman tal sociedad. Por su parte, Taylor ve la contraposición que se da entre la formulación de los derechos individuales a iguales libertades y la real garantía de tales identidades. Al contraponer la universalización de los derechos subjetivos y la consideración de las diferencias culturales, pone en entredicho la neutralidad ética frente a las concepciones particulares del bien, neutralidad propuesta por teorías liberales como las de Rawls y Habermas.

Frente a la neutralidad demandada por los liberales universalistas, Taylor y Walzer señalan la necesidad que tiene el Estado de derecho de fomentar determinadas concepciones particulares del bien. Sin embargo, Habermas explica que las limitaciones a los derechos fundamentales que la neutralidad protege, son propuestas por los comunitaristas al no entender correctamente la teoría de los derechos individuales, que creen ciega ante las diferencias culturales. Para Habermas es claro que el principio de igual respeto por los individuos sí garantiza la posibilidad que tiene cada quien para llevar a cabo su proyecto personal de vida, de acuerdo con la concepción de bien, propia de su comunidad cultural. Si se pretende, como los comunitaristas, que el Estado debe proteger ciertas concepciones y abandonar entonces su neutralidad, se niega la autolegislación según la cual los destinatarios del derecho sólo pueden serlo si se consideran los mismos autores de las leyes. El paternalismo descubierto por Habermas en la base del comunitarismo establece una dicotomía entre autonomía privada y autonomía pública, división que conlleva la dificultad de establecer los criterios para saber cuándo "lo igual ha de tratarse igual y lo desigual de forma desigual" (Habermas, 1999, p. 194). 
El reconocimiento de los derechos individuales comprende la integridad del individuo de una manera tal, que incluye los contextos particulares de vida que configuran su identidad, por esta razón, dice Habermas, el sistema de derechos individuales sí atiende a las desiguales condiciones de vida de las clases sociales y garantiza las diferencias culturales entre los grupos particulares. La igualdad jurídica garantiza, pues, la diferencia fáctica en la medida que concede una libertad de acción que puede ser ejercida de manera diferente por cada uno como miembro de una comunidad particular.

Aunque Habermas concede que para hacer uso de la igualdad jurídica debería contarse con una igualdad fáctica en las condiciones materiales de vida, no considera que deba introducirse una intervención que en aras del igualitarismo limite la libertad necesaria para configurar la vida de manera autónoma. Para él la dicotomía introducida por los comunitaristas desconoce la conexión que hay entre Estado de derecho y democracia, pero también la que hay "entre los derechos subjetivos de las personas privadas y la autonomía pública de los ciudadanos participantes en el proceso legislativo" (Habermas, 1999, p. 195).

La dificultad de armonizar la igualdad con la diferencia en el Estado de derecho se evidencia en las consecuencias ambivalentes de conquistas en el terreno de la equidad, como las logradas por los movimientos feministas ${ }^{7}$. Los resultados de estos logros en el terreno de la igualdad muestran cómo la libertad deviene limitaciones para ella misma. Ante esta dificultad Habermas advierte que es el paternalismo estatal el que genera restricciones a la libertad por orientarse de acuerdo con estereotipos tradicionales de identidad

7 El acceso al empleo, por ejemplo, ha redundado en feminización de la pobreza y en la desprotección de la prole. sexual o cultural y propone que se haga una interpretación adecuada de las necesidades reales diferenciadas por la identidad de género o de cultura.

Para Habermas las luchas por la identidad de un género particular generan para los miembros de los demás géneros una mejor interpretación de su propia identidad y modifica su rol social, pero en el caso de las luchas que reivindican la identidad colectiva de minorías étnicas y culturales oprimidas, los demás grupos no tienen por qué modificar su propio papel, a no ser que se trate de grupos étnicos que fuerzan los estados nacionales a conceder espacios para ejercer formas de autonomía como la lingüística. La dificultad que surge en las luchas de las minorías étnicas de un estado nacional es que vistas desde otro patrón, son mayorías que pueden oprimir a otros grupos presentes en el espacio geográfico que ocupan, como claramente ocurre en las comunidades negras e indígenas con respecto a sus componentes femeninos.

El derecho criticado por Taylor, cuya propuesta es tanto jurídica como política, es formal, individualista, positivo y coactivo, pero democrático, en tanto establecido por un procedimiento democrático. Por esta razón, la respuesta de Habermas a estas críticas se concreta en una "concepción procedimental del derecho según la cual el proceso democrático debe asegurar simultáneamente la autonomía privada y la autonomía pública" (Habermas, 1999, p. 197). La respuesta de Habermas es contundente: las minorías deben participar políticamente a través de los individuos que las conforman. No hay Estado de derecho sin democracia y por eso, antes que el Estado garantice algún trato especial para cierto grupo, los miembros de éste deben hacer uso de su autonomía ciudadana mediante discusiones públicas a propósito del trato igual y diferente que se requiere en diversos planos de su vida. 
Al parecer de comunitaristas como Walzer y Taylor, es necesario introducir otro tipo de liberalismo que garantice los derechos fundamentales pero que no subordine los bienes colectivos a los derechos individuales y proteja tradiciones particulares. Ante esta propuesta Habermas advierte que los argumentos en favor de los bienes colectivos deben ser expresados, entonces, en términos de derechos, pues la atención de fines colectivos "no puede disolver la estructura del derecho, ni puede destruir la forma jurídica" (Habermas, 1999, p. 205). Es cierto que la normativización de los modos de conducta debe abrirse por medio del derecho a la voluntad política de la sociedad, pero para él "todo ordenamiento jurídico es también la expresión de una forma de vida particular y no sólo el reflejo especular del contenido universal de los derechos fundamentales" (Habermas, 1999, p. 205).

Para Habermas la protección de la integridad del sujeto jurídico tiene como condición necesaria "el estricto tratamiento igual -dirigido por los propios ciudadanos-de los contextos de vida que aseguran su identidad" (Habermas, 1999, p. 197). Desde su punto de vista, la igualdad garantiza entonces la diferencia. La perspectiva moral juzga si algo es bueno para todos de la misma manera, pero no puede juzgar las valoraciones fuertes que los grupos hacen desde su particular perspectiva estableciendo si algo es bueno para ellos a partir de su propia identidad ética y política. Como las normas jurídicas regulan la interacción humana en sociedades concretas, el liberalismo tradicional exige la neutralidad ética del derecho para que no procure objetivos colectivos y deje a salvo la libertad, el bienestar y la seguridad de cada ciudadano visto individualmente.

Según Habermas, el ordenamiento jurídico expresa la autocomprensión, la vida y la idea de bien de una colectividad determinada, pues en el proceso comunicativo de construcción del derecho no sólo se esgrimen argumentos morales sino también se recurre a argumentos éticos. Por esta razón los comunitaristas se equivocan al ver paralelamente la voluntad política de una sociedad y la autocomprensión ético-política de grupos particulares, pues son estas comunidades determinadas al lugar en que se realiza el derecho. "La teoría de los derechos de ninguna manera les prohíbe a los ciudadanos del Estado democrático de derecho que hagan valer en su ordenamiento estatal general una concepción del bien que comparten desde el inicio o que acuerdan mediante los discursos políticos" (Habermas, 1999, p. 208).

Cuando una minoría logra reconocimiento jurídico y autonomía, por ejemplo para decidir la lengua y la religión en que deben ser educados sus miembros, el problema no desaparece, pues surgen otros grupos minoritarios que hacen vindicaciones frente dicha comunidad que ante ellos aparece como una mayoría dominante. El problema no se encuentra en la neutralidad ética del derecho moderno sino en la tensión que genera el carácter cultural de todo ordenamiento jurídico. Las ideas particulares sobre el bien están incluidas en el derecho gracias a la participación democrática con que éste se construye y esto imprime un carácter cultural a tal proceso de configuración jurídica. Esta visión parece haber sido la que posibilitó en Colombia el reconocimiento de la pluralidad cultural en la Constitución de 1991, que estableció la participación política de las comunidades indígenas y negras en el poder legislativo.

Son muchos los elementos de análisis aportados por la discusión entre los liberales comunitaristas a los que preocupan los derechos colectivos y los liberales universalistas que fundamentan su discurso en los derechos individuales, pero merece especial atención la preocupación comunitarista por la forja de la propia identidad y su relación con el reconocimiento por parte de los otros. También 
debe subrayarse la importancia dada por los universalistas a la participación política de todo ciudadano, incluidos los miembros de las comunidades culturales marginadas históricamente, como condición de legitimidad para toda legislación y ordenamiento político.

\section{La Constitución de 1991 y el reconocimiento del pluralismo cultural}

En la actual legislación colombiana se encuentra de alguna manera, quizás incipiente todavía, expresada la política comunitarista del reconocimiento al lado de la política universal de la no discriminación, con lo que se redirecciona la dinámica histórica de marginación y desconocimiento cultural que ha acompañado el proceso de la forja de la identidad nacional. Sin embargo, se trata de un proceso largo que hunde sus raíces en los comienzos del siglo XX y que sólo se verá realizado en las conquistas a favor de la pluralidad cultural que se logren a nivel jurídico y político durante el siglo que está comenzando.

Desde comienzos del siglo XX, algunos sectores de la sociedad colombiana habían reconocido la dignidad de la condición indígena y promovieron una visión dignificante de su cultura. "Algunos de ellos veían en la indianidad la fuente de la nacionalidad, mientras que otros pensaron el resguardo como el germen de la futura organización socialista" (Pineda, 2002, p. 13). El Instituto Indigenista Colombiano, fundado en 1941 promocionó la reivindicación de la dignidad de los pueblos indígenas y promovió un nuevo horizonte para la política indigenista en Colombia. Esta política se institucionalizó con la creación de la Oficina de Negocios Indígenas, establecida durante el Frente Nacional, que dio origen a la División de Asuntos Indígenas del Ministerio de Gobierno. La ley 135 de 1961 abrió la posibilidad de crear nuevos resguardos, empresa que fue posible gracias a las acciones estatales proyectadas desde el Instituto Colombiano para la Reforma Agraria (INCORA).

Como resultado del procesual abandono de la idea de civilizar a los indios y el empoderamiento de las comunidades indígenas, estas comunidades no sólo consiguieron nuevos resguardos, sino lograron reducir la injerencia aniquilante de iglesias, entre ellas la iglesia católica, sobre sus tradiciones. Es así como vieron que desde 1978 el Ministerio de Educación "asumió la etnoeducación como política oficial para los pueblos indígenas, promoviendo la educación bilingüe e intercultural" (Pineda, 2002, p. 13). Estos antecedentes prepararon el terreno para la ratificación del convenio 169 de la Organización Internacional del Trabajo (OIT), referente a la autonomía de los pueblos indígenas y para que en la Constitución de 1991 se propusiera a las comunidades indígenas como sujetos de derechos colectivos y se les asignara dos plazas en el Senado.

Además de prohibir la esclavitud así como toda forma de servidumbre y de trata de seres humanos, la Constitución de 1991 (art. 17) afirma que "el Estado reconoce y protege la diversidad étnica y cultural de la Nación colombiana" y que al lado del castellano, idioma oficial, "las lenguas y dialectos de los grupos étnicos son también oficiales en sus territorios" (art. 10), razones por las cuales la enseñanza impartida en las comunidades con tradiciones lingüísticas propias debe ser bilingüe.

De esta manera la Constitución de 1991 establece que Colombia es un país multi-étnico y pluri-cultural, rompiendo con el paradigma tradicional de la homogeneidad cultural bajo el cual había sido concebida la organización de la sociedad colombiana.

Haciendo un justo reconocimiento a la composición multi-étnica de la 
nacionalidad colombiana, la Constitución de 1991 le dio funciones jurisdiccionales a las autoridades indígenas en los conflictos que se susciten entre los miembros de su respectivo grupo, por hechos ocurridos dentro de su jurisdicción, siempre que con ello no se contradiga la filosofía general que informa la Constitución (Garay, 2002, p. 223).

Estos cambios se enmarcan en la dinámica de reconocimiento de la pluralidad cultural que se dio en América Latina durante los años noventa y que produjo como resultado para las comunidades indígenas: "el reconocimiento a sus propias formas de gobierno, el derecho al territorio y el ejercicio de formas de jurisdicción propias" (Villa, 2001). En el caso colombiano esto se puede entender por la composición pluralista de la Asamblea Constituyente de 1991, que permitió proponer un orden constitucional "que controlara la arbitrariedad estatal, favoreciera la participación de nuevas fuerzas políticas, estimulara el pluralismo y lograra mayor justicia social” (Uprimny, 2001, p. 97). El Estado Social de Derecho apareció entonces como una herramienta que se complementaba con el multiculturalismo para hacer realidad la justicia social y el aprecio de las diferencias ${ }^{8}$.

8 En agosto de 1993, Leonor Zabalata, una indígena colombiana de la Sierra Nevada de Santa Marta, solicitaba ante la Subcomisión de la Prevención de Discriminación y Protección de las Minorías de la Organización de las Naciones Unidas con las siguientes palabras: "Necesitamos que las sectas y religiones abandonen nuestras tierras porque nosotros tenemos nuestras propias religiones y formas de pensamiento... Es urgente oponerse a la asimilación forzosa que nos han impuesto. Nuestros pueblos tienen derecho a considerarse diferentes y ser respetados como pueblos diferentes" (Schlegelberger, 1995, p. 47).
Se puede ver que la Constitución de 1991 significó un cambio radical en lo que concierne a los derechos de los indígenas, pero no se puede decir lo mismo de los grupos afro-descendientes dado que la Asamblea Constituyente no incluyó delegados suyos y sólo los mencionó en el Artículo transitorio 55. Este artículo, que reconoció a las comunidades negras como grupos étnicos, anunció la creación de mecanismos para la protección de su identidad cultural y de sus derechos colectivos. Además proyectó el fomento de su desarrollo económico y social, "con el fin de garantizar que estas comunidades obtengan condiciones reales de igualdad de oportunidades frente al resto de la sociedad colombiana" (Helg, 2004, p. 38).

Este artículo transitorio fue convertido por la Comisión Especial de Comunidades Negras en la ley 70 de 1993, que reconoce la propiedad colectiva ancestral de las comunidades negras, les concede dos plazas en la Cámara de Representantes y promueve su identidad cultural así como su desarrollo económico. No obstante, este reconocimiento se limita a las comunidades asentadas en las riberas de la Costa Pacífica sin abarcar a los grupos negros de otras regiones ni a las comunidades de zambos y de mulatos. "En realidad, la definición de comunidades negras está inspirada en la de comunidades indígenas [...] las tierras de las comunidades negras son definidas como baldías, no como suyas; los negros están considerados como pobladores, no como propietarios... [y] se les da el derecho a la propiedad colectiva, no comunal" (Helg, 2004, pp. 38-39). De esta suerte, a las comunidades negras no se les concedió el derecho al gobierno local ni funciones jurisdiccionales, como se concedió a los indígenas.

No deja de ser irónico que justo cuando se promulgaba esta ley, en el Urabá chocoano se desencadenara una profunda crisis humanitaria a causa del desplazamiento forzoso de 
comunidades afro-colombianas, producido por las masacres que evidenciaban el avance de los grupos armados de la derecha en la región. "Hoy buena parte de los desplazados por la fuerza son dueños tanto de territorios colectivos creados al amparo de la Ley 70 de 1993, como de entidades territoriales indígenas" (Arocha, 2004, pp. 160-161).

Estos hechos evidencian que pese al pluralismo sin precedentes alcanzado por la Asamblea Constituyente, no se logró un tratamiento igualitario para los grupos culturales integrantes de la gran comunidad política colombiana y que el Estado Multicultural Social de Derecho en Colombia sigue siendo un proyecto en construcción. Para hacer realidad este Estado, todavía es necesario superar las violaciones a los derechos humanos y la impunidad, pero no menos la desigualdad, la pobreza y la miseria, fenómenos todos que siguen estando asociados a factores étnicos y culturales, pues "¿quién puede razonablemente negar que la falta de alimentación, salud, vivienda o educación afecta la dignidad humana, y por ende disminuye la capacidad de las personas para ser ciudadanos autónomos?" (Uprimny, 2001, p. 106).

Si bien la Constitución de 1991 representa un avance en el proceso de consolidación del Estado Multicultural Social de Derecho en Colombia, su implementación no ha logrado todavía los resultados esperados por la sociedad colombiana, que en su elaboración experimentó un cambio renovador hacia el pluralismo. Las causas de la insuficiente aplicación de las nuevas leyes y la incapacidad del Estado para velar por los derechos individuales y colectivos consagrados en la Carta de 1991 pueden obedecer a diferentes razones, entre ellas algunas relacionadas con elementos del entorno tales como "la globalización, el narcotráfico, la continuación del conflicto armado" (Uprimny, 2001, p. 100), pero luego de más de diez años de vigencia las evidencias acusan una falta de compromiso tanto del Estado como de la sociedad civil con sus propios logros.

En el análisis sobre los alcances de la legislación colombiana de cara al multiculturalismo, es necesario evitar dos extremos: "la tendencia a eliminar toda importancia a los diseños institucionales, o el vicio opuesto de considerar que todos los problemas sociales pueden ser resueltos por una simple ingeniería constitucional" (Uprimny, 2001, p. 102). Lo cierto es que gracias a la ampliación del horizonte legislativo en Colombia, la Corte Constitucional, uno de los entes creados en 1991, ha tenido que habérselas con cuestiones que exigen una ampliación de los instrumentos de análisis y de juicio tradicionales, así lo expresa el Senador Carlos Gaviria cuando afirma:

En materia de pluralismo, y específicamente en el ámbito de las jurisdicciones constitucionales, la Corte Constitucional ha tenido que enfrentar desafíos sorprendentes pero estimulantes, apelando a herramientas conceptuales que los juristas distamos mucho de manejar con destreza por ser propias de las ciencias sociales empíricas (Sánchez, 2001).

La salvaguarda de la libertad y de la igualdad en Colombia, al lado de los derechos colectivos de las minorías históricamente discriminadas es un deber irrenunciable y debe ser subrayado en el momento presente, en que "la administración del presidente Álvaro Uribe Vélez podría fortalecer el monoculturalismo, proceso antecedido por la proliferación de guerreros en todos los territorios étnicos de la Nación, cuya consecuencia lógica ha sido el destierro, siempre de la mano de la expansión de la frontera agrícola" (Arocha, 2004, p. 160). 
Hay que tomar en serio las críticas que desde el comunitarismo se hacen a las versiones rígidas del liberalismo, pero también las que se hacen al Estado benefactor. Sin embargo, no es posible abandonar los ideales de justicia social que encarna el Estado de Derecho ni la importancia de inculturar adecuadamente sus políticas en las comunidades indígenas y negras que conforman la riqueza cultural de Colombia.

La experiencia colombiana evidencia los límites de la legislación liberal basada tradicionalmente en los derechos individuales, pero señala un avance enorme en la lucha por el reconocimiento de la diversidad, pues "no es siempre fácil construir un orden político fundado en la diversidad, ni armonizar el respeto a la diferencia cultural con la protección de derechos fundamentales que se consideran universales" (Uprimny, 2001, p. 105). Está abierto el horizonte político para que en los próximos años el reconocimiento del pluralismo cultural se concrete en políticas públicas que beneficien a las mujeres, a los negros y a los indígenas para lograr así la forja de una identidad nacional incluyente que permita a la sociedad colombiana superar el estado fragmentario al que la ha conducido su largo proceso histórico de discriminación y de desconocimiento.

\section{Referencias}

Colmenares, G. (1989). La economía y la sociedad coloniales 1550 - 1800. En Nueva Historia de Colombia. Vol. 1. Bogotá: Planeta.

Constitución Política de Colombia de 1991. www.presidencia.gov.co

Garay, L. (2002). Repensar a Colombia. Hacia un nuevo contrato social. Talleres del milenio. Bogotá: Tercer Mundo.
Gaviria, C. (s.t.) (2001). En Sánchez, E. \& Jaramillo, I. La jurisdicción especial indígena. Bogotá: Procuraduría General de la Nación. www.alertanet.org

Habermas, J. (1999). La lucha por el reconocimiento en el estado democrático de derecho. En La inclusión del otro. Barcelona. Paidós.

Helg, A. (2004). Constituciones y prácticas sociopolíticas de las minorías de origen africano. En Arocha, J. Utopía para los excluidos. El multiculturalismo en África y América Latina. Bogotá: Universidad Nacional de Colombia.

Jaramillo, R. (1998). La postergación de la experiencia de la modernidad en Colombia. En Colombia: la modernidad postergada. Bogotá: Argumentos.

Melo, G. (1986). La Constitución de 1886: un acuerdo sobre lo fundamental. En Boletín cultural y Bibliográfico. Volumen XXIII. Bogotá: Banco de la República. www. banrep.gov.co

Palacios, J. (1989). La esclavitud y la sociedad esclavista. En Nueva Historia de Colombia. Vol. 1. Bogotá: Planeta.

Pineda, R. (2002, febrero). Estado y pueblos indígenas en el siglo XX. La política indigenista entre 1886 y 1991. En Credencial historia, 142. Bogotá.

Rawls, J. (1996). La justicia como equidad: política, no metafísica. En Revista La Polítca, 1. Barcelona: Piados.

Rojas, M. (1997, jul-dic). La formación de la identidad nacional en la Colombia de mediados del siglo XIX. En Universitas Humanística, 46. Bogotá: Pontificia Universidad Javeriana.

Sánchez, E. \& Jaramillo, I. (2001). La jurisdicción especial indígena. Bogotá: 
Procuraduría General de la Nación. www. alertanet.org

Schlegelberger, B. (1995). Los arhuacos en defensa de su identidad y autonomía. Resistencia y sincretismo. Bogotá: Centro Editorial Javeriano.

Taylor, Ch. (2001). El multiculturalismo y la política del reconocimiento. México: FCE.
Villa, W. (2001). El Estado multicultural y el nuevo modelo de subordinación. En Seminario de Evaluación. Diez años de la Constitución Colombiana 1991-2001. Bogotá: Facultad de Derecho, Ciencias Políticas y Sociales. Universidad Nacional de Colombia.

Uprimy, R. (2001). Constitución de 1991, Estado social y derechos humanos: promesas incumplidas, diagnósticos y perspectivas. En Seminario de Evaluación: Diez años de la Constitución Colombiana 1991-2001. Bogotá. 